\title{
Lipid Lowering and Antioxidant Activities of Methanolic Extract of Ficus hispida Linn. Fruits in Cholesterol Fed Rats
}

\author{
M. S. Hossain, S. Dutta, S. Parvin, M. E. Islam* \\ Department of Pharmacy, Rajshahi University, Rajshahi-6205, Bangladesh \\ Received 24 February 2018, accepted in final revised form 24 May 2018
}

\begin{abstract}
The present study was designed to evaluate the effect of fruits extracts (Ficus hispida) on serum lipids and antioxidant status in hypercholesterolaemic rats. Hyperlipidemia was induced by feeding high fat diet for 28 days and was evidenced by elevated levels of serum triglycerides (TG), serum LDL cholesterol and decreased serum HDL cholesterol. Oxidative stress was measured by determining the activity of antioxidant enzymes like superoxide dismutase (SOD), catalase (CAT), and amount of thiobarbituric acid reactive substances (TBARS) in liver homogenate of experimental rats. In hypercholesterolaemic rats, crude methanolic extract (CME) consumption had no effect on HDL-cholesterol, yet it showed a marked hypolipidaemic action, decreasing TG and LDL-cholesterol that had been increased after consuming the high-cholesterol diet. On the other hand, the concentration of TBARS decreased significantly, indicating decreased lipid peroxidation. In addition, the activities of catalase and SOD increased significantly in liver homogenate. The above evidence suggested that CME of the fruits of this plant can be a source of natural antioxidant that can reduce the plasma lipid (cholesterol) level and also decreases the lipid peroxidation.
\end{abstract}

Keywords: Ficus hispida; Hyperlipidemia; In-vivo antioxidant; Oxidative stress; Lipid peroxidation; Antioxidant enzyme.

(C) 2018 JSR Publications. ISSN: 2070-0237 (Print); 2070-0245 (Online). All rights reserved.
$\begin{array}{ll}\text { doi: http://dx.doi.org/10.3329/jsr.v10i3.35686 } & \text { J. Sci. Res. } 10 \text { (3), 303-314 (2018) }\end{array}$

\section{Introduction}

Recently there has been a great deal of attention toward the field of free radical chemistry specially due to the increased evidence of free radical induced diseases like neurodegenerative disorders such as Alzheimer's disease, cardiovascular diseases, cancer etc. Free radicals reactive oxygen species and reactive nitrogen species are generated by our body by various endogenous systems, exposure to different physiochemical conditions or pathological states. A balance between free radicals and antioxidants is necessary for proper physiological function. If free radicals overwhelm the body's ability

*Corresponding author: ekram@ru.ac.bd 
to regulate them, a condition known as oxidative stress ensues [1-4]. Lipids are highly prone to free radical damage resulting in lipid peroxidation that can lead to adverse alterations [5]. Free radical damage to protein can result in loss of enzyme activity. Damage caused to DNA, can result in mutagenesis and carcinogenesis [6].

Enhanced oxidative stress is a serious condition that may also be classified as novel risk factors. Low-density lipoprotein (LDL) cholesterol is an established risk factor for coronary heart disease (CHD). In the presence of oxidative stress LDL particles can become oxidized to form a lipoprotein species that is particularly atherogenic $[7,8]$. Lipid peroxidation induced by free radicals has been implicated in the pathogenesis of various diseases. Numerous in vitro and animal studies show that oxidative modification of low density lipoprotein (LDL) is an important initial event of atherosclerosis [9].

Nature has endowed us with protective antioxidant mechanisms- superoxide dismutase (SOD), catalase, glutathione, glutathione peroxidases and reductase, vitamin $\mathrm{E}$ (tocopherols and tocotrienols), vitamin C etc., apart from many dietary components [10].

The search for antioxidant compounds is increasing to prevent the chronic damages by free radicals now days. Like other medicine, nature is the predominant source for searching the new miracle to prevent such damages for many years [11].

F. hispida which is locally called Kakdumur is a small tree and is very common throughout Bangladesh in homestead and village thickets. Traditionally, different parts of the plant have been used in the treatment of ulcers, psoriasis, anemia, piles jaundice, vitiligo, hemorrhage, diabetes, convulsion, hepatitis, dysentery, biliousness, and as lactagogue and purgative [12,13]. Various scientific works like antineoplastic, cardioprotective, neuroprotective and anti-inflammatory effects have been published to establish the scientific basis of traditional medicinal values attributed to $F$. hispida [1417]. But, according to best of our knowledge there is no scientific evidence on in vivo or in vitro antioxidant activity and lipid lowering activity of fruits of this plant. Very recently we have studied the in vitro antioxidant activity of the fruits of this plant and results showed that the methanol extract and fractions may have a significant antioxidant activity [18].

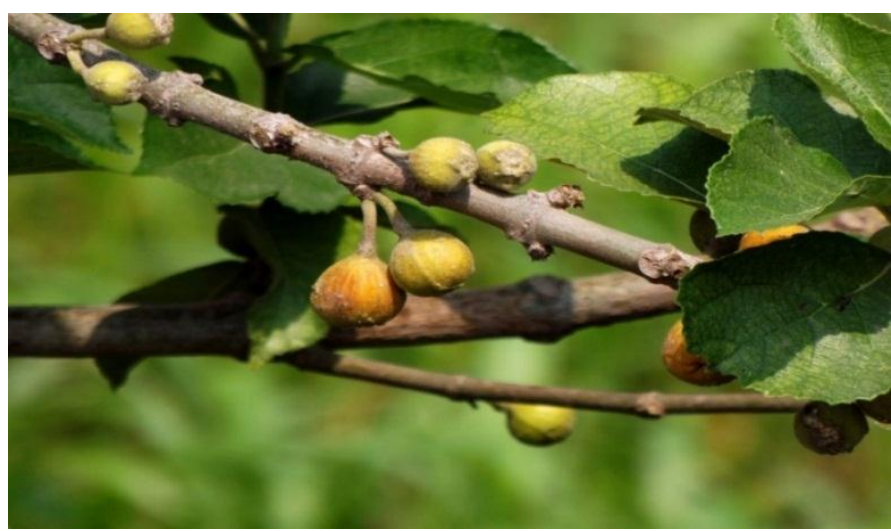

FicusHispida Linn. fruit 
It is natural that plant metabolites contain varieties of phyto-constituents which can show in vitro antioxidant activity. So it is essential to confirm the above activity by in vivo method. In connection with this we carried out in vivo antioxidant activity on hyperlipidaemia induced rat model as increased lipid level can increase the oxidative stress by generating free radical [19]. So this study aims to evaluate the in vivo antioxidant as well as lipid lowering activity of fruits extract of $F$. hispida for future investigation toward the finding of new, potent and safe compound that can prevent the generation of free radical from lipid as well as lowers the lipid level

\section{Materials and Methods}

\subsection{Plant material}

The fruits of $F$. hispida were collected from Dinajpur district, Bangladesh in September and were identified by the taxonomist of Bangladesh National Herbarium, Mirpur, Dhaka, Bangladesh. A voucher specimen was deposited in the herbarium unit with accession no. BNB-345. The fruits were sliced, air dried, powdered and stored in airtight container.

\subsection{Extract preparation}

The dried powder $(700 \mathrm{~g}$ ) was macerated in $2.0 \mathrm{~L}$ of $99.8 \%$ methanol. After 15 days the the entire mixture then underwent a coarse filtration by a piece of clean, white cotton material. The extract then was filtered through Whatman ${ }^{\circledR}$ filter paper (Bibby RE200, Sterilin Ltd., UK). The resulting filtrates were then evaporated in a rotary evaporator at 40 ${ }^{\circ} \mathrm{C}$ and a brown semisolid mass (32 g) of the extract was obtained. The crude methanolic extract (CME) was used for in vivo antioxidant and lipid lowering activities.

\subsection{Experimental animals}

Albino rats of either sex (125-140 g) were used for the study. The rats were purchased from the animal research branch of Pharmacy Department, Jahangirnagar University. After the purchase, they were maintained at standard laboratory conditions and fed with commercial pellet diet and normal water. The experiments were performed based on animal ethics guidelines of Institute of Biological Sciences (IBSc), University of Rajshahi, Bangladesh. The study protocol was approved by Institutional Animal, Medical Ethics, Biosafety and Biosecurity Committee (IAMEBBC) at the Institute of Biological Sciences, University of Rajshahi, Bangladesh.

\subsection{Experimental design}

Twenty four Albino rats were randomly divided into six groups of four each and kept in their cages for five days prior dosing to allow for acclimatization to the laboratory 
condition. The experimental hyperlipidaemia was induced by feeding high fat diet (containing fat $24 \mathrm{~g} \%$, protein $20 \mathrm{~g} \%$, starch $41 \mathrm{~g} \%$, cholesterol, minerals and vitamins). The drugs were administered in constant volume of $1 \mathrm{~mL} / 100 \mathrm{~g}$ body weight. The control group animals received the vehicle in the same volume. Group-1: Administered vehicle and served as normal control, Group-2: Fed with high fat diet and served as hyperlipidaemia control. Group-3: Received standard drug Vitamin-E (100 IU / rat) along with the high fat diet. Group-4, 5 and 6 received CME of 100, 250 and $500 \mathrm{mg} / \mathrm{kg}$, p.o., respectively, with high fat diet. On day 28 , animals were anaesthetized by phenobarbitone sodium. Blood samples and livers were collected to determine the plasma lipid profile and antioxidant activities.

\subsection{Estimation of plasma lipid profile}

The plasma/serum collected from the rats were assayed for the estimation of the level of low density lipoprotein (LDL), high density lipoprotein (HDL), and triglycerides by the commercially available kits (HUMAN ${ }^{\circledR}$, Germany \& Plasmatech Laboratories ${ }^{\circledR}$, UK).

\subsection{Estimation of triglyceride}

The triglyceride level was determined by the triglyceride precipitating reagent from HUMAN $^{\circledR}$, Germany. $2 \mathrm{~mL}$ of the reagent was mixed with $20 \mu \mathrm{L}$ sample and standard. They were mixed well and kept at RT for $10 \mathrm{~min}$. The reagent was used as the blank to measure the absorbance at $500 \mathrm{~nm}$. Triglyceride concentration was measured as follows:

Concentration of triglyceride $=\frac{\Delta \text { A Sample }}{\Delta A \text { Standard }} \times 200(\mathrm{mg} / \mathrm{dL})$

\subsection{Estimation of LDL cholesterol}

The LDL cholesterol level was determined by the LDL cholesterol precipitating reagent from Plasmatech ${ }^{\circledR}$ Laboratories, UK. $2 \mathrm{~mL}$ of the reagent was mixed with $200 \mu \mathrm{L}$ sample and standard. They were mixed well and kept for $10 \mathrm{~min}$. Then they were centrifuged at $4000 \mathrm{rpm}$ for $10 \mathrm{~min}$. Now $200 \mu \mathrm{L}$ supernatant was mixed with $2 \mathrm{~mL}$ of the reagent and kept at room temperature for $10 \mathrm{~min}$. The absorbance was measured at 500nm using blank containing dil. water instead of sample. The LDL cholesterol level was calculated as follows:

Concentration of LDL Cholesterol $=\frac{\Delta \text { A Sample }}{\Delta \text { A Standard }} \times$ Standard concentration $(\mathrm{mg} / \mathrm{dL})$

\subsection{Estimation of HDL cholesterol}

The HDL cholesterol level was determined by the HDL cholesterol precipitating reagent from HUMAN ${ }^{\circledR}$, Germany. $2 \mathrm{~mL}$ of the reagent was mixed with $1 \mathrm{~mL}$ sample or standard. They are mixed well and kept at RT for $10 \mathrm{~m}$. Then they were centrifuged at $4000 \mathrm{rpm}$ for 
$10 \mathrm{~min}$. Then $200 \mu \mathrm{L}$ clear supernatant was mixed with $2 \mathrm{~mL}$ reagent. Incubate at $37{ }^{\circ} \mathrm{C}$ for $5 \mathrm{~min}$. The absorbance was measured at $500 \mathrm{~nm}$ using blank containing distilled water instead of sample. The HDL cholesterol level was calculated as follows:

Concentration of HDL Cholesterol $=\frac{\Delta \text { A Sample }}{\Delta \text { A Standard }} \times 150(\mathrm{mg} / \mathrm{dL})$.

\subsection{Antioxidant enzyme activities}

CAT and SOD activities were evaluated in liver tissue. The preparation of the enzyme source fraction was as follows. One gram of liver tissue from each rat was washed in ice cold isotonic physiologic saline solution and then homogenized in ice cold buffer and centrifuged at $5000 \mathrm{rpm}$ for $15 \mathrm{~min}$. The supernatants were removed and stored at $-80{ }^{\circ} \mathrm{C}$ for analysis. The protein content in supernatant was measured according to the method of Lowry using bovine serum albumin as standard.

Superoxide dismutase (SOD) activity was measured according to the method of Marklund and Marklund [20,21]. Briefly, $2.5 \mathrm{~mL}$ Tris-EDTA (pH 8.5), $100 \mu \mathrm{L}$ pyrogallol $(2 \mathrm{mM})$ were taken into a cuvette and scanned for $3 \mathrm{~min}$. Again, $2.8 \mathrm{~mL}$ Tris-EDTA (pH8.5), $100 \mu \mathrm{L}$ pyrogallol $(2 \mathrm{mM})$ and $50 \mu \mathrm{L}$ supernatant were taken into a curette and initial absorbance reading was recorded at $440 \mathrm{~nm}$ after $1 \mathrm{~min}$ of incubation. Absorbance reading was recorded exactly after $3 \mathrm{~min}$. SOD activity was calculated by the following formula and one unit was determined as the amount of enzyme that inhibited the oxidation of pyrogallol by $50 \%$. The activity was expressed as units per milligram of protein.

$\%$ of inhibition $=\frac{\text { Initial absorbance }- \text { final absorbance }}{\text { Initial absorbance }} \times 100$

Enzyme unit $(\mathrm{U})=\frac{\% \text { of inhibition }}{50} \times$ common dilution factor

Catalase activity (CAT) was measured based on Aebi's method [22]. Briefly, $20 \mu \mathrm{L}$ of the supernatant was added to a cuvette containing $780 \mu \mathrm{L}$ of a $50 \mathrm{M}$ potassium phosphate buffer ( $\mathrm{pH} 7.4$ ), and then the reaction was initiated by adding $200 \mu \mathrm{L}$ of $500 \mathrm{mM} \mathrm{H}_{2} \mathrm{O}_{2}$ to make a final volume of $1.0 \mathrm{~mL}$ at $25{ }^{\circ} \mathrm{C}$. The decomposition rate of $\mathrm{H}_{2} \mathrm{O}_{2}$ was measured at $240 \mathrm{~nm}$ for $1 \mathrm{~min}$ on a spectrophotometer. CAT activity was calculated by the following formula and the activity was expressed as moles of hydrogen peroxide reduced/min/mg protein.

$\%$ of inhibition of $\mathrm{H}_{2} \mathrm{O}_{2}=\frac{\text { Initial absorbance-final absorbance }}{\text { Initial absorbance }} \times 100$

\subsection{Lipid peroxidation assay}

Lipid peroxidation was estimated by the malon dialdehyde (MDA) method of Park et al. [23]. $200 \mu \mathrm{L}$ of a $10 \%(\mathrm{w} / \mathrm{v})$ solution of the liver homogenate was mixed with $600 \mu \mathrm{L}$ of distilled $\mathrm{H}_{2} \mathrm{O}$ and $200 \mu \mathrm{L}$ of $8.1 \%$ (w/v) SDS. The mixture was vortexed and incubated at 
room temperature for $5 \mathrm{~min} .1 .5 \mathrm{~mL}$ of $20 \%$ acetic acid $(\mathrm{pH} 3.5)$ and $1.5 \mathrm{~mL}$ of $0.8(\mathrm{w} / \mathrm{v})$ TBA were added to above mixture and heated. Then the mixture was cooled and $1.0 \mathrm{~mL}$ of distilled water and $5.0 \mathrm{~mL}$ of a butanol/pyridine $(15: 1 \mathrm{v} / \mathrm{v})$ solution were added and vortex. The tubes were centrifuged at $4000 \mathrm{rpm}$ for $15 \mathrm{~min}$, and the resulting pink coloured layer was measured spectrophotometrically at $532 \mathrm{~nm}$.

\section{Results and Discussion}

\subsection{Effect on serum triglyceride (TG) level}

The presence of triglycerides in biological system can result in an increase in oxidative stress. So a decrease in the triglycerides level may be an indication of decreased oxidative stress [24]. Rats fed with HF diet had serum TG level of $256.79 \pm 17.73 \mathrm{mg} / \mathrm{dL}$. There was a significant elevation of TG level in HF diet rats when compared to serum TG level in normal control rats $(153.62 \pm 9.90 \mathrm{mg} / \mathrm{dL})$. HF diet rats treated with reference standard Vitamin-E had serum TG level of 109.05 \pm 7.0. On the other hand, hyperlipidemic rats treated with CME $(100 / 250 / 500 \mathrm{mg} / \mathrm{kg}$, p.o.) had serum TG level of $126.58 \pm 8.39$, $142.29 \pm 9.89$ and $121.75 \pm 8.04 \mathrm{mg} / \mathrm{dL}$, respectively and these values were significantly lower when compared to serum TG level in HF diet rats $(256.79 \pm 17.73 \mathrm{mg} / \mathrm{dL})$ (Fig. 1). So, in this study, CME showed dose dependent decrease in serum triglyceride level as compared to that of HF diet rats. This may be due to the antioxidant property of the plant extract.

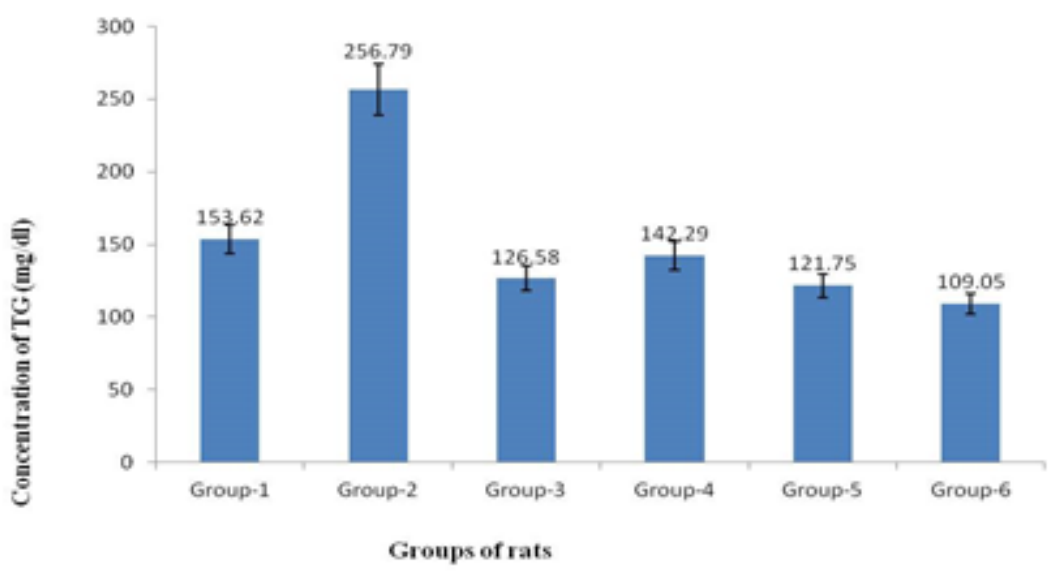

Fig. 1. Effect of CME and reference standard Vitamin-E on triglyceride level.

\subsection{Effect on serum LDL cholesterol (serum LDL-C) level}

LDL cholesterol is a major determinant of oxidative stress because this cholesterol is called the bad cholesterol and is responsible for many diseases [25]. The serum LDL-C levels measured at the end of the experiment in different groups of rats are shown in Fig. 
2. Rats with HF diet resulted in a significant increase of LDL-C $(761.68 \pm 111.7 \mathrm{mg} / \mathrm{dL})$. However, a significant decrease at the level of LDL-C was observed with the increase of dose of CME. The measured LDL-C for three different doses 100, 250 and $500 \mathrm{mg} / \mathrm{dL}$ were $449.97 \pm 29.19,248.33 \pm 9.68$ and $194.56 \pm 8.01 \mathrm{mg} / \mathrm{dL}$ respectively. On the other hand, Vitamin-E treated rats also showed a significant decrease of LDL-C level (235.86 \pm 18.21$)$ as compared to HF diet induced rats.

Treatment of the hyper-lipidemia induced rats shows a dose dependent decrease in the LDL cholesterol level as compared to the negative control $(761.68 \pm 111.7 \mathrm{mg} / \mathrm{dL})$ and the result shows similarity with standard antioxidant vitamin-E.

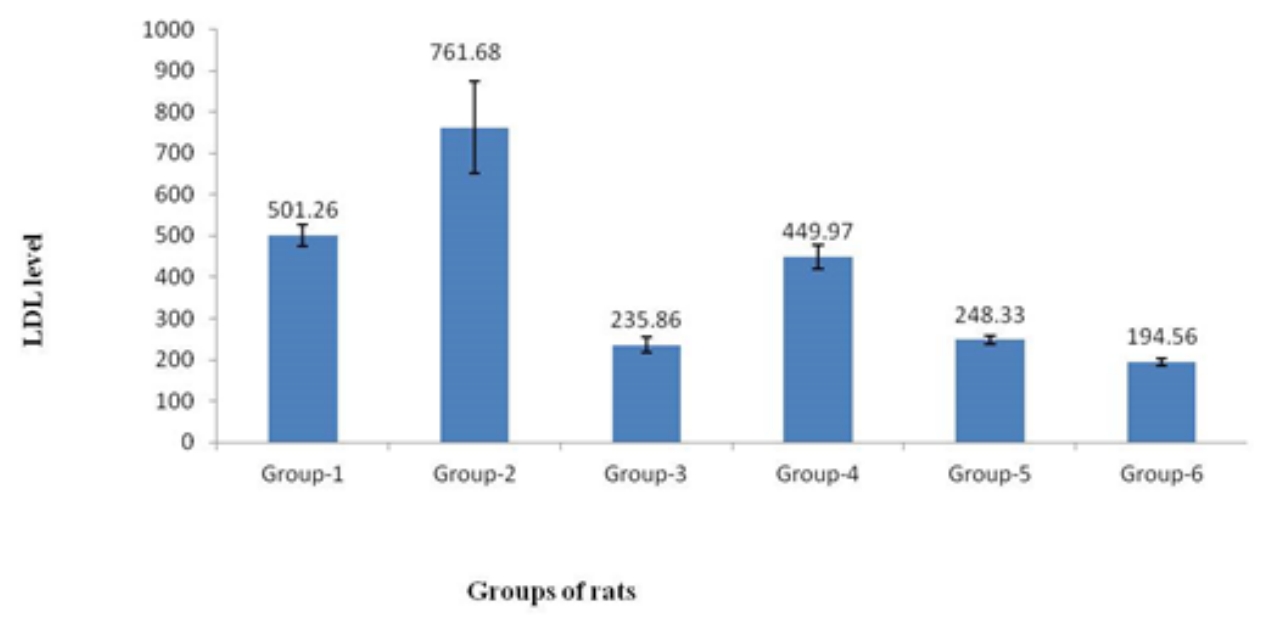

Fig. 2. Effect of CME and reference standard Vitamin-E on LDL-C level of different groups of rats.

\subsection{Effect on serum HDL cholesterol (serum HDL-C) level}

While LDL cholesterol is considered as the bad cholesterol, HDL cholesterol is called the good cholesterol as they oppose coronary diseases directly, by removing cholesterol from foam cells, by inhibiting the oxidation of LDLs, and by limiting the inflammatory processes that underlie some coronary diseases [26]. The serum HDL-C levels measured at the end of the experiment in different groups of rats are shown in Fig. 3. Rats fed with HF had serum HDL-C level of $36.47 \pm 2.93 \mathrm{mg} / \mathrm{dL}$, which was significantly lower when compared to serum HDL-C level in normal control rats $71.97 \pm 10.67 \mathrm{mg} / \mathrm{dL}$. HF diet rats treated with reference standard Vitamin-E had serum HDL-C level of 121.61 \pm 8.18 $\mathrm{mg} / \mathrm{dL}$, which was significantly higher than HF diet control rats $(36.47 \pm 2.93 \mathrm{mg} / \mathrm{dL})$. Administration of CME at different doses (100, 250 and $500 \mathrm{mg} / \mathrm{dL}$ p.o.) also significantly increased the level of HDL-C 85.02 $\pm 19.78,125.14 \pm 12.37$ and $165.38 \pm 15.76$ $\mathrm{mg} / \mathrm{dL}$ compared to the serum HDL-C level of HF diet control rats. Current study shows an opposite result of LDL cholesterol level to that of HDL cholesterol level because a 
gradual increase in level of HDL cholesterol was found upon treatment and increase in dose.

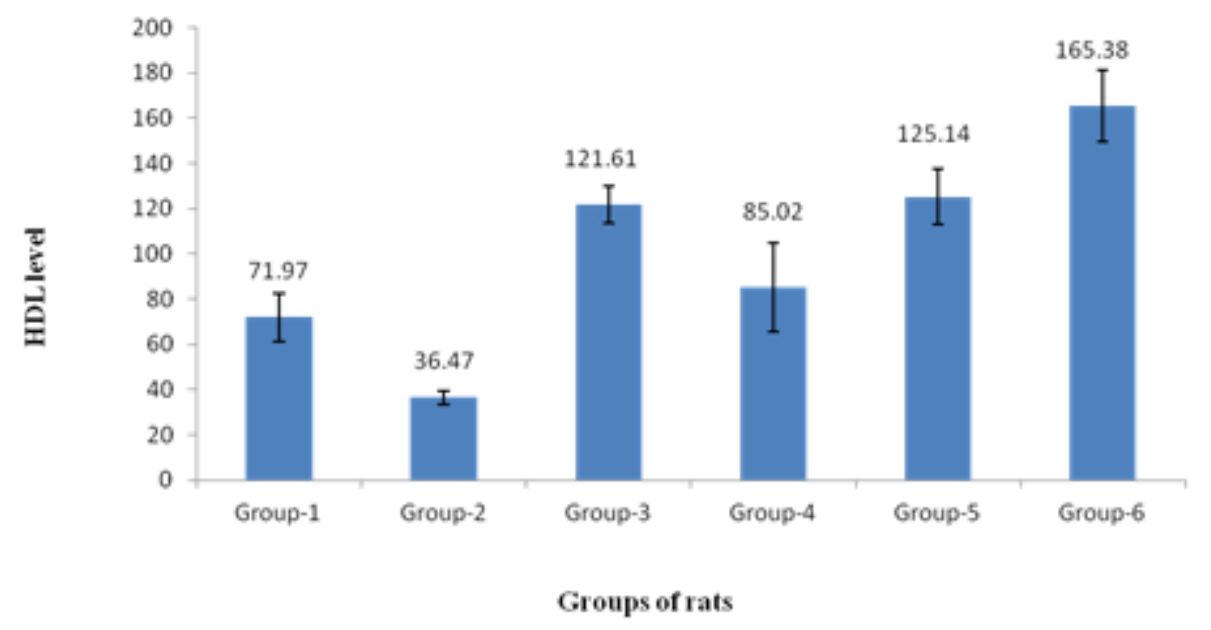

Fig. 3. Effect of CME and reference standard Vitamin-E on HDL-C level of different groups of rats.

\subsection{Hepatic antioxidant enzyme activities}

\subsubsection{Superoxide dismutase (SOD) assay}

Antioxidant polyphenolic compounds have a key role in the detoxification of reactive oxygen species (ROS) and help to maintain cellular balance. An increased SOD level indicates an increase in the oxidative stress [27]. The results of in vivo determination of SOD activity for various groups of rats (Group-1 to Group-6) are presented in Fig. 4. Administration high fat diet significantly decreased the activity of SOD.

Treatment of rats with CME significantly inhibit the SOD activity which increases with the increase of dose as group- 6 showed largest inhibition of SOD level $(14.76 \pm 1.26 \%)$ and Group-4 showed lowest inhibition $(7.35 \pm 0.90 \%)$. Again, normal control showed inhibition of $10.06 \pm 0.35 \%$ and Vitamin-E treated rat showed a decrease of $11.28 \pm 1.21 \%$. So a gradual increase in inhibition of SOD level during the study indicates a decrease in oxidative stress as well as antioxidant property of the plant extract. 


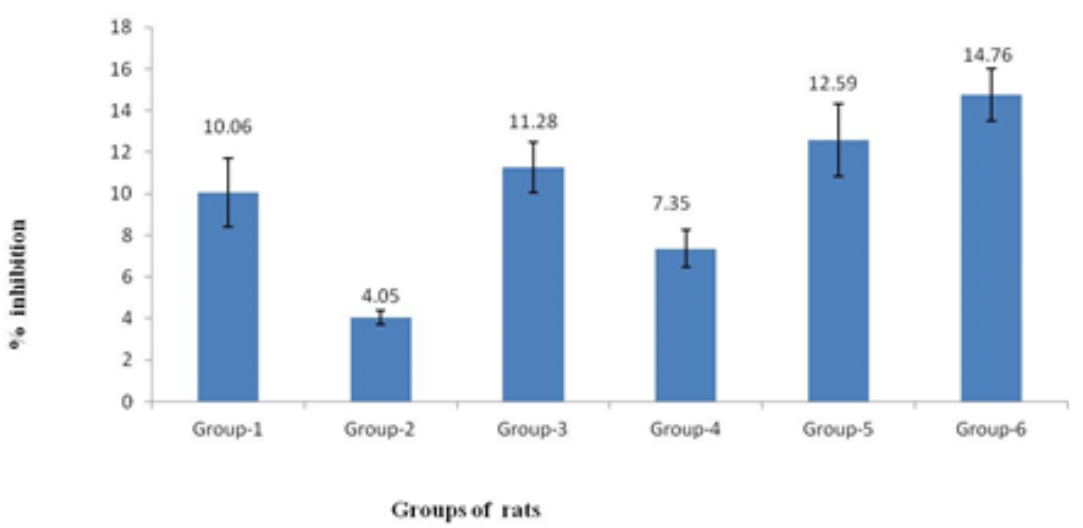

Fig. 4. Comparison of inhibition of SOD activity of different groups of rats treated with CME and reference standard Vitamin-E.

\subsubsection{Catalase activity assay}

Catalase is an important liver enzyme that can inhibit the free radicals responsible for oxidative stress and an increase in catalase level indicates the decrease in free radical as well as increased antioxidant activity [28]. The activity of antioxidant enzyme catalase in different groups of rats is shown in Fig. 5. Significance decrease in catalase activity (value) was observed in liver homogenate of hyperlipidaemia rats $(6.88 \pm 0.96 \%)$ compared to that obtained for the control grouped rats $(11.16 \pm 0.43 \%)$. Treatments with CME of Ficus hispida fruit extract and vitamin-E improved catalase activity compared to hyperlipidaemia rats. At different dose of CME like 100, 250 and $500 \mathrm{mg} / \mathrm{kg}$ the observed enzyme activity measured in units $/ \mathrm{mg}$ of protein was $0.19,0.18$ and 0.25 respectively and inhibition of $\mathrm{H}_{2} \mathrm{O}_{2}$ was $9.67 \pm 1.28 \%, 9.85 \pm 2.42 \%$ and $12.40 \pm 0.62 \%$ respectively. Moreover, the activity of $\mathrm{CME}$ at maximum dose was higher than positive control group (Vitamin-E treated rats) which showed inhibition of $8.14 \pm 2.80 \%$. So the present study shows a positive result towards the antioxidant activity of fruit extract from Ficus hispida.

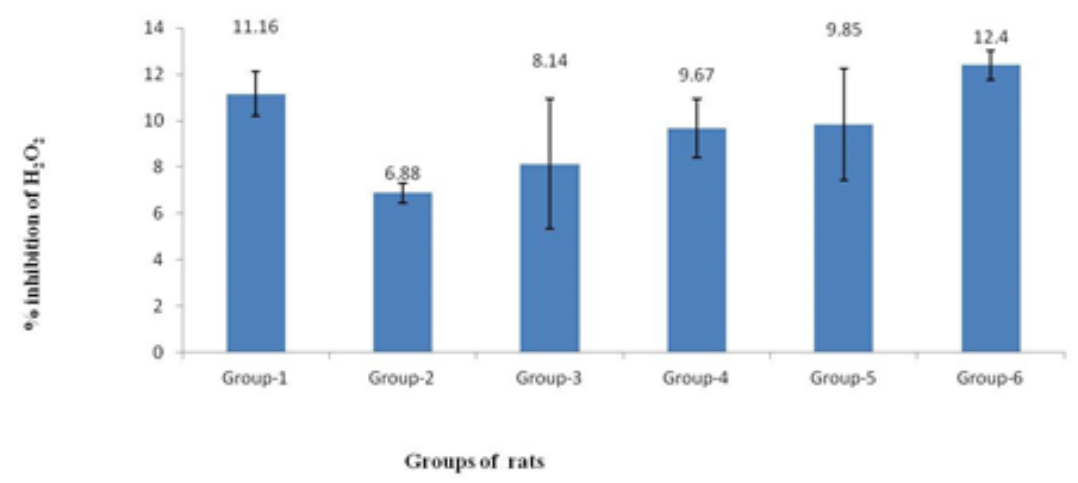

Fig. 5. Comparison of catalase activity of different groups of rats treated with $\mathrm{CME}$ at different concentrations. 


\subsubsection{Lipid peroxidation assay}

Reactive oxygen species can react with the polyunsaturated fatty acids of lipid membranes and induce lipid peroxidation. A decrease in lipid peroxidation can be a very good indicator of decrease in oxidative damage $[29,30]$. TBARS level was considerably varied high in rats with high fat diet comparing to the normal control group $(31.69 \pm 3.45$ $\mathrm{nmol} / \mathrm{mg}$ protein). The increased MDA content might have resulted from an increase of reactive oxygen species (ROS) as a result of stress due hyperlipidaemia. After 28 days of treatment with CME a significant decrease in TBARS levels has been observed. Similarly, level of TBARS was decreased towards the normal level with standard drug Vitamin-E treated rats (Fig. 6). The high fat diets of rats would cause the increase of lipidperoxidation and expose the animal to oxidative stress. TBARS is a good indication of lipid peroxidation. The above result indicates that the protective role of CME against oxidative damage in vivo might be due to the decrease of lipid peroxidation.

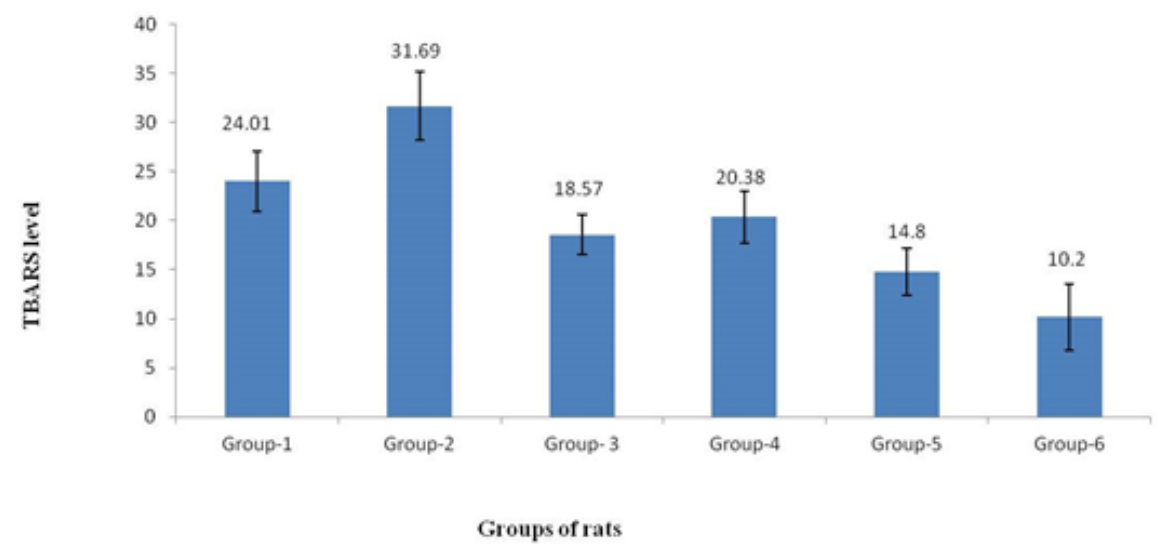

Fig. 6. TBATS level of different groups of rats after treatment with CME of Ficus hispida fruits.

\section{Conclusion}

The crude methanolic extract of the plant exhibited dose dependent decrease in oxidative stress which is reflected by the decrease in triglyceride, LDL cholesterol, superoxide dismutase and TBARS level as well as the increase in HDL cholesterol level and catalyse activity. The above results indicate that, the plant extract can be a potential candidate for further research to find out some new and effective option to manage the oxidative stress as well as diseases induced by free radicals.

\section{Abbreviations}

F. hispida: Ficus hispida; HDL: High density lipoprotein; CAT: catalase; SOD: superoxide dismutase; TBARS: thiobarbituric acid reactive substances; IBSc: Institute of Biological Sciences; IAMEBBC: Institutional Animal, Medical Ethics, Biosafety and 
Biosecurity Committee; MDA: malon dialdehyde; TBA: thiobarbituric acid; TG: triglyceride.

\section{Acknowledgment}

The author would like to thank the animal research branch of Pharmacy Department, Jahangirnagar University for providing the rats.

\section{References}

1. V. Lobo, A. Patil, A. Phatak, and N. Chandra, Pharmacogn. Rev. 4, 118 (2010). https://doi.org/10.4103/0973-7847.70902

2. R. Khalid, Clin. Interv. Aging. 2, 219 (2007).

3. G. I. Ulku, O.Nilufer, A. Levent, and A. J. Mustafa, Food Biochem. 41, 124 (2017).

4. U. Bayani, V. S. Ajay, Z. Paolo and R. T. Mahajan, Curr. Neuropharmacol. 7, 65 (2009). https://doi.org/10.2174/157015909787602823

5. Y. Huiyong and X. Libin, Chem. Rev. 111, 5944 (2011).https://doi.org/10.1021/cr200084z

6. M. Dizdaroglu and P. Jaruga, Free Radic. Res. 46, 382 (2012). https://doi.org/10.3109/10715762.2011.653969

7. R. S. Rosenson, Atherosclerosis 173, 1 (2004). https://doi.org/10.1016/S0021-9150(03)00239-9

8. S. Gupta, S. Sodhi, and V. Mahajan, Exp. Opin. Ther. Tar. 13, 889 (2009). https://doi.org/10.1517/14728220903099668

9. N. Etsuo, J. Clin. Biochem. Nutr. 48, 3 (2011).

10. T. P. Devasagayam, J. C. Tilak, K. K. Boloor, K. S. Sane, S. S. Ghaskadbi, and R. D. Lele, J. Assoc. Physic. India 52, 794 (2004).

11. S. Yevgenia, I. David, K.T. Yael, D. Zvy, and Y. Yaron, Food Nutr. Sci. 4, 643 (2013). https://doi.org/10.4236/fns.2013.46083

12. P. Kanika, S. M. K. Pandit, and A. M. Bhagwat, Int. J. Pharm. Sci. Res. 3, 188 (2011).

13. P. L. Ephraim, M. P. Helena, D. P. Alison, and A. N. Robert, J. Ethnopharmacol. 119, 195 (2008). https://doi.org/10.1016/j.jep.2008.06.025

14. B. Pratumvinit, T. Srisapoomi, P. Worawattananon, N. Opartkiattikul, W. Jiratchariyakul, and T. Kummalue, J. Med. Plant. Res. 3, 255 (2009).

15. A. Mohammad and C. Nisha, Pharmacogn. Rev. 5, 96 (2011). https://doi.org/10.4103/0973-7847.79104

16. F. Ahmed and A. Urooj, Pharm. Biol. 50, 468 (2012). https://doi.org/10.3109/13880209.2011.613848

17. D. Sivaraman, P. Muralidharan, and P. Panneerselvam, Int. J. Pharmacol. 8, 212 (2012).

18. M. S. Hossain, S. Dutta, S. Parvin, M. S. I. Mahbub, and M. E. Islam, J. Sci. Res. 8, (2016). https://doi.org/10.3329/jsr.v8i3.26711

19. K. A. Turkdogan, O. Akpinar, M. Karabacak, H. Akpinar, F. T. Turkdogan, and O. Karahan, J. Pak. Med. Assoc. 64, 379 (2014).

20. T. Biju, R. Amita, R. P. Ballamajalu, and K. Suchetha, J. Ind. Soc. Periodontol. 18, 451 (2014). https://doi.org/10.4103/0972-124X.138686

21. S. Marklund and G. Marklund, Eur. J. Biochem. 47, 469 (1974). https://doi.org/10.1111/j.1432-1033.1974.tb03714.x

22. E. Niki, Biofactors 34, 171 (2008). https://doi.org/10.1002/biof.5520340208

23. S. Y. Park, S. H. Bok, S. M. Jeon, Y. B. Park, S. J. Lee, T. S, Jeong, and M. S. Choi, Nutr. Res. 22, 283 (2002). https://doi.org/10.1016/S0271-5317(01)00398-0

24. S. Al-Benna, C. A. Hamilton, J. D. McClure, P. N. Rogers, G. A. Berg, I. Ford, C. Delles, and A. F. Dominiczak, Arterioscler Thromb. Vasc. Biol. 26, 218 (2006). 
https://doi.org/10.1161/01.ATV.0000193626.22269.45

25. A. Katsuki, Y. Sumida, H. Urakawa, E. C. Gabazza, S. Murashima, K. Nakatani, Y. Yano, and Y. Adachi, Diabet. Care 27, 631 (2004).https://doi.org/10.2337/diacare.27.2.631

26. Y. Liang, S. S. Qu, C. X. Wang, G. L. Zou, Y. L. Wu, and D. H. Li, Chem. Eng. Sci. 55, 6071 (2000). https://doi.org/10.1016/S0009-2509(00)00142-1

27. H. H. Draper and M. Hadley, Methods Enzymol. 186, 421 (1990). https://doi.org/10.1016/0076-6879(90)86135-I

28. P. V. Sravani, N. K. Babu, K. V. Gopal, G. R. Rao, A. R. Rao, B. Moorthy, and T. R. Rao, Ind. J. Dermatol. Venereol. Leprol. 75, 268 (2009). https://doi.org/10.4103/0378-6323.48427

29. B. Giuseppina, ISRN Oncol. ID 137289 (2012). https://doi.org/10.5402/2012/137289

30. P. Barter, Eur. Heart J. Suppl. 7, F4 (2005). https://doi.org/10.1093/eurheartj/sui036 